\title{
First parasitological survey of Endangered Bornean elephants Elephas maximus borneensis
}

\author{
Stephanie Hing ${ }^{1, *}$, Nurzhafarina Othman ${ }^{2,3}$, Senthilvel K. S. S. Nathan ${ }^{2,4}$, Mark Fox ${ }^{5}$, \\ Matthew Fisher ${ }^{6}$, Benoit Goossens ${ }^{2,3,4}$ \\ ${ }^{1}$ Department of Life Sciences, Imperial College London, London, UK \\ ${ }^{2}$ Organisms and Environment Division, School of Biosciences, Cardiff University, Cardiff, UK \\ ${ }^{3}$ Danau Girang Field Centre, Sabah Wildlife Department, Kota Kinabalu, Sabah, Malaysia \\ ${ }^{4}$ Sabah Wildlife Department, Kota Kinabalu, Sabah, Malaysia \\ ${ }^{5}$ The Royal Veterinary College, London, UK \\ ${ }^{6}$ Department of Infectious Disease Epidemiology, Imperial College London, London, UK
}

\begin{abstract}
Relatively few studies have been carried out on the parasites of free-ranging wild animal species, which has led to a lack of baseline parasitological data. This is a concern because endoparasites can have an important influence on fitness and survival, particularly in small populations of endangered species. This field study is the first parasitological survey of Endangered Bornean elephants Elephas maximus borneensis. Using a special modification of the McMaster method, trematode, cestode and nematode ova were identified in the faeces of wild Bornean elephants in 2 key range areas in Sabah, Malaysian Borneo: the Tabin Wildlife Reserve and the Lower Kinabatangan Wildlife Sanctuary. Preliminary comparisons between the sites suggest that prevalence, load and diversity vary between the two, leading to hypotheses on host, parasite and environmental factors which may affect endoparasite infection dynamics in wild Bornean elephants. This study provides an initial catalogue of parasite types in the Bornean elephant and reports on endoparasite prevalence and load, valuable baseline data for future research.
\end{abstract}

KEY WORDS: Bornean elephant - Endoparasites · Trematode · Cestode · Nematode . Anoplocephala $\cdot$ Fasciola

Resale or republication not permitted without written consent of the publisher

\section{INTRODUCTION}

There is a dearth of baseline parasitology data available for wild animal species (Mathews 2009). Despite the significance of parasites in wildlife population health, their relevance in conservation has generally been neglected (Gómez et al. 2012). The majority of English language conservation textbooks published between 1970 and 2009 made no mention of parasites (Nichols \& Gómez 2011). Calls are growing for re.search to improve our understanding of parasites in conservation because parasites can play an important role in ecosystem function, host evolution, fitness and survival, especially in small populations of endangered species (Lafferty 1997, Gregory \& Hudson 2000, Marcogliese 2004, Whiteman \& Parker 2005, Gillespie \& Chapman 2006, Gómez et al. 2012, Suzan et al. 2012).
Parasites are any organisms that live in or on a host, deriving benefit at the expense of the host. For the purposes of this study, the term 'parasites' is used to refer to endoparasites of the gastrointestinal tract and hepatobilliary system, for example, strongyle nematodes and liver flukes. Parasites can shape presence, absence, population size and viability either directly, affecting host fecundity, morbidity and mortality, or indirectly, for example, via host debility and influence on immunocompetence (Gulland 1995, Hechinger \& Lafferty 2005, Nichols \& Gómez 2011). Giant panda, a flagship for wildlife conservation, provide a stark illustration of how parasites can affect species survival. Currently, the most significant threat to wild panda is nematode parasite infection (Zhang et al. 2008).

Parasites are also important in conservation as they can serve as a non-invasive warning system for 
wildlife and habitat health because environmental changes impact upon hosts, parasites and their shared environment (Lafferty 1997, Marcogliese 2005). In 2012 for the very first time, a chapter in a conservation textbook was dedicated to links between habitat loss, habitat fragmentation and infectious disease ecology (Suzan et al. 2012). Habitat loss and fragmentation can affect infection dynamics via a variety of mechanisms, including hindering animal movement, impeding gene flow (Coulon et al. 2004), facilitating edge effects (Chapman et al. 2006a), introducing environmental contamination (Deem et al. 2001), altering the ecology of intermediate hosts (Page et al. 2001), changing host population size and density (Mbora \& McPeek 2009), limiting nutrition (Chapman et al. 2006b), facilitating contact and conflict with people (Nelson et al. 2003), and subjecting animals to psychological and physiological stress, thereby affecting immunocompetence (McCallum \& Dobson 2002). Parasites have the potential to be used as indicators of stress in wildlife threatened by habitat fragmentation (Schwitzer et al. 2010).

The main threats to the survival of Bornean elephants Elephas maximus borneensis (Fig. 1), and indeed Asian elephants E. maximus on the mainland, are anthropogenic habitat loss and fragmentation (Ambu et al. 2012). Asian elephants, including Bornean elephants, are listed by the IUCN as Endangered (Choudhury et al. 2008). Bornean elephants are morphometrically distinct, with larger ears, longer tails, straighter tusks and a more rounded body shape than Asian elephants on the mainland (Othman et al. 2008). Arguably, Bornean elephants are a genetically distinct subspecies of Asian elephant and constitute an evolutionary significant conservation unit (Fernando et al. 2003). Regardless of their origins, Bornean elephants are a conservation priority as an iconic flagship and umbrella species carrying out vital ecosystem services (Campos-Arceiz \& Corlett 2011). An estimated 2040 (95\% CI: 1184-3652) Bornean elephants remain confined to 4 managed ranges, including the 2 study sites of the present study: the Lower Kinabatangan Wildlife Sanctuary (LKWS) and the Tabin Wildlife Reserve (TWR) (Alfred et al. 2010).

No previously reported studies have included parasites of endangered Bornean elephants, captive or wild. Indeed, surveys to assess parasite prevalence and load in Asian elephants are seldom reported in the literature. Collating data largely from captive Asian elephants, Fowler \& Mikota (2006) catalogued parasites including: trematodes or liver flukes (Fasciola spp.), cestodes or tapeworms (Anoplocephala spp.) and various gastrointestinal nematode or round-

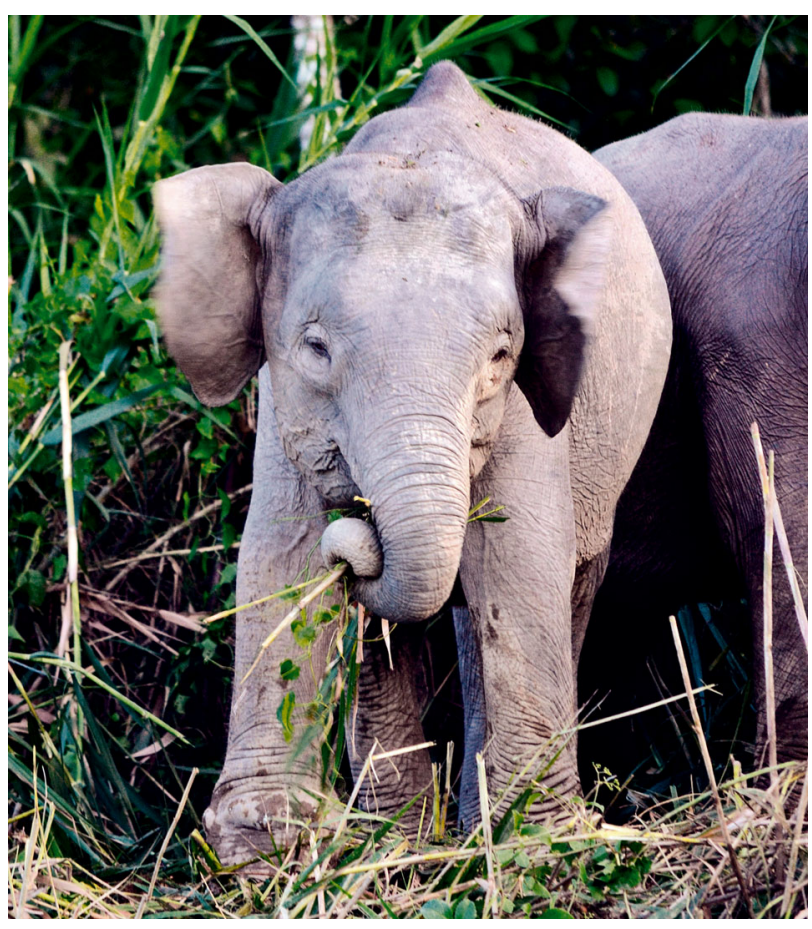

Fig. 1. A wild Bornean elephant calf. Photo: Stephanie Hing

worm species (strongyle type, including Murshidia, Quilonia, Bathmostomum, Grammocephalus and Equinurbia). These parasites in Asian elephants may be associated with pathology, clinical disease, increased morbidity and mortality. Gastrointestinal nematode infection is associated with frequent clinical illness, including colic, diarrhoea and dependent oedema in Asian elephants managed in captivity in Kerala, India (Saseendran et al. 2004, Chandrasekharan et al. 2009), and in Asian elephants in the Myanmar timber industry, gastrointestinal roundworms and liver flukes directly account for $8 \%$ of deaths $(n=2806)$ and contribute to $13 \%$ of deaths associated with 'weakness' (Mar 2007).

Neglect of parasite research in conservation and the practical challenges of field parasitology have precluded surveys of wild Asian elephants in range countries. This study addresses the absence of baseline data on parasites of endangered species and is the first parasite survey in endangered Bornean elephants.

\section{MATERIALS AND METHODS}

\section{Study sites}

The LKWS $\left(5^{\circ} 18^{\prime} \mathrm{N}\right.$ to $5^{\circ} 42^{\prime} \mathrm{N}, 117^{\circ} 54^{\prime} \mathrm{E}$ to $118^{\circ}$ $33^{\prime} \mathrm{E}$ is a highly fragmented mosaic of forest patches 
in an agricultural-dominated landscape with significant ongoing anthropogenic impact including villages, small-scale agriculture, oil palm plantations and a busy tourism industry. The LKWS is home to an estimated 298 elephants (95\% CI: 152-581) at a density of 2.15 Bornean elephants per $\mathrm{km}^{2}$ (Alfred et al. 2010). The population density of Bornean elephant in the LKWS is very high, when it is considered that the minimum viable area for Asian elephants is 0.5 to 1.5 elephants per $\mathrm{km}^{2}$ (Sukumar 2003).

The TWR $\left(5^{\circ} 10 \mathrm{~N}\right.$ to $5^{\circ} 15 \mathrm{~N}, 118^{\circ} 30^{\prime} \mathrm{E}$ to $118^{\circ} 45^{\prime} \mathrm{E}$, the largest continuous in Sabah with an area of approximately $1200 \mathrm{~km}^{2}$, consists of secondary dipterocarp forest and scattered pockets of remnant primary forest. The TWR has a total population of 342 Bornean elephants (95\% CI: 152-774) at a density of 0.6 individuals per $\mathrm{km}^{2}$ (Alfred et al. 2010).

\section{Sample collection}

During the dry season, 104 faecal samples were collected from free-ranging wild Bornean elephants in the LKWS $(n=52)$ and the TWR $(n=52)$ (Fig. 2). The approximate location of wild Bornean elephants was ascertained using data from satellite collars and reports from local contacts. Animals were tracked on foot using VHF radio tracking and indirect signs including footprints, dung piles and evidence of feeding on vegetation. The latitude and longitude of sample collection sites were recorded using a handheld GPS (Garmin GPS MAP 60CSx).

Freshly deposited faeces were identified for collection by appearance (colour, consistency and observed insect activity). Core samples were collected from faecal boluses of different sizes to reduce contamination by soil nematodes. Several boluses in a dung pile were sampled to ensure that the resulting pooled sample was representative. To minimise duplication, i.e. the inadvertent repeated collection of faecal samples from the same individuals, elephants were observed and boluses of different sizes were sampled from dung piles located at a distance of at least $5 \mathrm{~m}$ from one another. Samples were collected in labelled, pre-prepared polyethylene specimen containers containing $95 \%$ ethanol. Ethanolfixed faecal samples were centrifuged to maximise parasite detection (Blag- burn \& Butler 2006), supernatant was removed and the wet weight was recorded.

\section{Sample analysis}

Samples were analysed following published protocols for the special modification of the McMaster method of faecal egg flotation to a sensitivity of 10 ova $^{-1}$ faeces (MAFF 1986). Parasite ova were observed using an Omax digital binocular compound light microscope (Model MD827S30 series) and photographs were captured with the microscopic imaging software ScopeImage 9.0 H3D. Ova were identified to phylum level based on morphology and morphometrics.

Prevalence, the number of positive cases as a percentage of the total number sampled, was calculated as an indication of how common parasite infection was in each population. Faecal egg count (FEC), an indirect measure of the parasite load of an individual host, was calculated in terms of eggs $\mathrm{g}^{-1}$ faeces (EPG). A diversity score of 1, 2 or 3 was assigned according to the number of parasite types observed in each sample, where 3 indicates the presence of ova of Fasciola, Anoplocephala and strongyle-type species.

\section{Statistical analysis}

Prevalence, load and diversity of parasites were compared between samples from the LKWS and the TWR. Using R 2.14.1, a chi-squared test was applied to compare parasite prevalence between sites and a Wil-

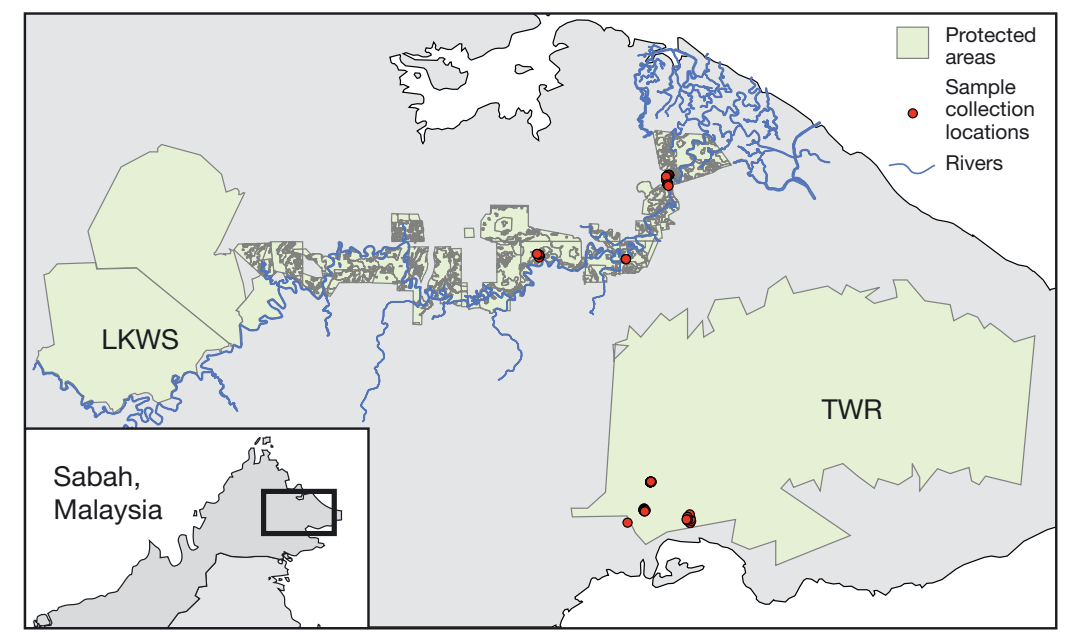

Fig. 2. Sample collection locations in the Lower Kinabatangan Wildlife Sanctuary (LKWS) and the Tabin Wildlife Reserve (TWR). Inset shows the study location in Sabah, Malaysia 
coxon Mann-Whitney $U$-test was employed to compare parasite load and diversity between sites. Using Microsoft Excel 2010, a variance to mean ratio (VAR), also known as a coefficient of dispersion, was calculated to assess the distribution of parasite load data.

\section{RESULTS}

Endoparasites were found to be ubiquitous in Bornean elephants, with all samples yielding at least one parasite ovum. Parasite phyla detected included trematodes, cestodes and nematodes. Trematodes were represented by Fasciola species (Fig. 3A), cestodes by Anoplocephala species (Fig. 3B) and nematodes by strongyle-type ova (Fig. 3C). Due to overlapping size of strongyle ova produced by different parasites, they could not be reliably identified to genus or species level.

\section{Prevalence}

Fasciola (liver fluke) was found to be the most prevalent endoparasite overall, with $70.2 \%$ (73 positive cases/104 total samples) of elephants infected. Strongyle (66.3\%, 69/104) and Anoplocephala $(50.0 \%, 52 / 104)$ infections were also frequently identified (Table 1).

In the LKWS, strongyle nematodes $(82.7 \%, 43 / 52)$ were the most prevalent endoparasites; Anoplocephala $(69.2 \%, 36 / 52)$ and Fasciola $(55.7 \%, 29 / 52)$ were also widespread. In the TWR, Fasciola $(84.6 \%$, $44 / 52)$ was the most prevalent endoparasite. Strongyles $(50.0 \%, 26 / 52)$ and Anoplocephala $(30.8 \%$, 16/52) were also common (Table 1).

A preliminary comparison between the prevalence of trematodes, cestodes and nematodes in the LKWS and the TWR revealed significant differences. The prevalence of Fasciola was significantly higher in the
TWR compared with the LKWS $\left(\chi^{2}=10.34\right.$, df $=102$, $\mathrm{p}<0.05)$. Conversely, the prevalence of strongyles $\left(\chi^{2}=4.98, \mathrm{df}=102, \mathrm{p}<0.05\right)$ and Anoplocephala $\left(\chi^{2}=\right.$ $15.38, \mathrm{df}=102, \mathrm{p}<0.05$ ) were significantly higher in the LKWS compared with the TWR (Table 1).

\section{Parasite load}

The load of each parasite type was significantly different between sites. The mean load of Fasciola was significantly higher in the TWR (238.0 EPG) than in the LKWS (86.2 EPG; Mann-Whitney test statistic $W=858.5, \mathrm{p}<0.05)$. Conversely, the mean load of strongyles was significantly higher in the LKWS (155.4 EPG) than in the TWR (81.3 EPG; $W=1873$, $\mathrm{p}<0.05)$. The mean load of Anoplocephala was also significantly higher in the LKWS (101.8 EPG) compared with the TWR (37.6 EPG; $W=1928.5, \mathrm{p}<0.05$; Table 2). For each parasite type in each location and parasite load data overall, VAR was $>1$, which is indicative of overdispersion.

\section{Mixed infection}

The majority of samples $(65.4 \%, 68 / 104)$ yielded more than one phylum of endoparasite, but mixed

Table 1. Prevalence of parasitic ova in the Lower Kinabatangan Wildlife Sanctuary (LKWS) and the Tabin Wildlife Reserve (TWR). Values in parentheses are the number of positive cases/the total number sampled

\begin{tabular}{|lccc|}
\hline \multirow{2}{*}{ Parasite type } & \multicolumn{3}{c|}{ Positive samples (\%) } \\
& LKWS & TWR & Total \\
\hline Fasciola & $55.7(29 / 52)$ & $84.6(44 / 52)$ & $70.2(73 / 104)$ \\
Anoplocephala & $69.2(36 / 52)$ & $30.8(16 / 52)$ & $50.0(52 / 104)$ \\
Strongyles & $82.7(43 / 52)$ & $50.0(26 / 52)$ & $66.2(69 / 104)$ \\
\hline
\end{tabular}

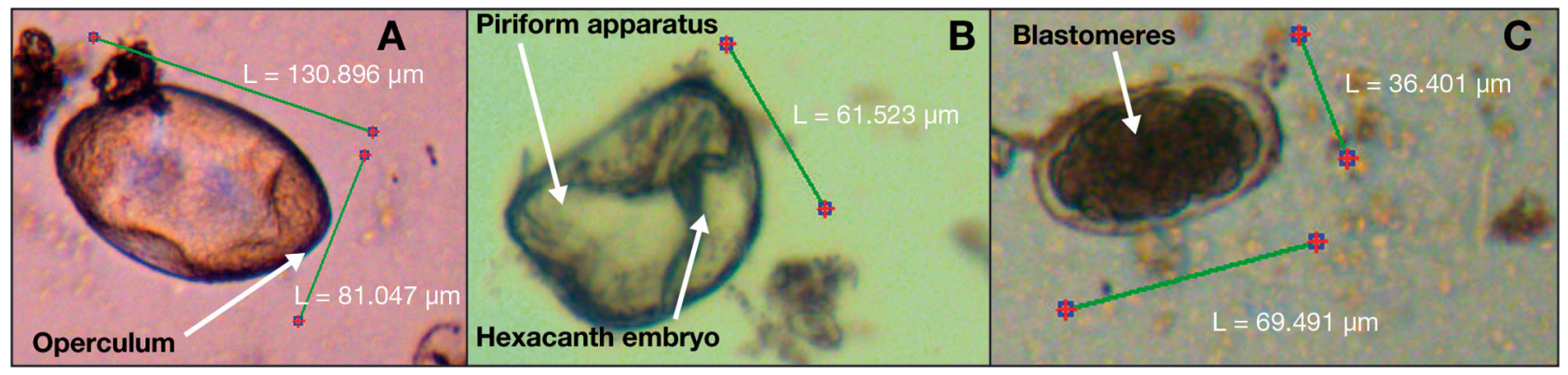

Fig. 3. Parasite ova identified in Elphas maximum borneenis. (A) Fasciola ovum; (B) Anoplocephala ovum; (C) strongyle-type ovum. Green lines show length (L) 
infections were more prevalent in the TWR $(80.8 \%$, 42/52) compared with the LKWS (50.0\%, 26/52; $\chi^{2}=10.83, \mathrm{df}=1, \mathrm{p}<0.05$; Table 3 ).

\section{DISCUSSION}

This study provides the first baseline data on endoparasites in wild Bornean elephants. All wild animals harbour parasites of some kind because hosts and parasites have coevolved over millennia, developing complex systems which can vary from commensal to highly virulent (Anderson \& May 1982, Toft \& Karter 1990, Taylor et al. 2013). While it is expected that Bornean elephants harbour parasites, the findings of this study have potential long-term health and conservation implications. Firstly, the high prevalence and load of strongyles and Anoplocephala in the LKWS and Fasciola in the TWR may have clinical significance, particularly if compounded by concurrent disease and other factors such as stress. The results also indicate a high potential for transmission of diseases spread via similar routes to the parasites identified. In addition, significant differences in parasite prevalence and load between fragmented and continuous habitat may be associated with anthropo-

Table 2. Parasite load (avg. no. of ova $g^{-1}$ faeces) in the Lower Kinabatangan Wildlife Sanctuary (LKWS) and the Tabin Wildlife Reserve (TWR)

\begin{tabular}{|lccc|}
\hline Parasite type & LKWS & TWR & $\begin{array}{c}\text { Mean load across } \\
\text { both sites }\end{array}$ \\
\hline Fasciola & 86.2 & 238.0 & 162.1 \\
Anoplocephala & 101.8 & 37.6 & 69.7 \\
Strongyles & 155.4 & 81.3 & 118.4 \\
Total mean load & 343.4 & 356.9 & 350.2 \\
\hline
\end{tabular}

Table 3. Mixed infections in the Lower Kinabatangan Wildlife Sanctuary (LKWS) and the Tabin Wildlife Reserve (TWR). A diversity score of 1, 2 or 3 was assigned according to the number of parasite types observed in each sample, where 3 indicates the presence of ova of Fasciola, Anoplocephala and strongyle-type species. Values in parentheses are the number of samples scoring a diversity score of 1,2 or $3 /$ the total number sampled

\begin{tabular}{|llll|}
\hline \multirow{2}{*}{ Site } & \multicolumn{4}{c|}{ Frequency of parasite diversity scores (\%) } \\
& \multicolumn{1}{c}{1} & 2 & 3 \\
\hline LKWS & $50.0(26 / 52)$ & $34.6(18 / 52)$ & $15.4(8 / 52)$ \\
TWR & $19.2(10 / 52)$ & $48.1(25 / 52)$ & $32.7(17 / 52)$ \\
$\begin{array}{c}\text { Total across } \\
\text { both sites }\end{array}$ & $34.6(36 / 104)$ & $41.3(43 / 104)$ & $24.0(25 / 104)$ \\
\hline
\end{tabular}

genic activities, and this warrants further investigation as part of the conservation management of Bornean elephants and their habitat.

The prevalence and load of each phylum will be discussed separately, as different types of parasites have different life cycles and routes of transmission and thus are affected by different host, parasite and environmental factors.

The results of this study agree with previous studies on trematodes in Asian elephants which indicate that Fasciola species are prevalent and present in high numbers. Trematodes are amongst the most frequently encountered endoparasites in captive Sumatran elephants (Stremme et al. 2007), and 33.8\% of semi-captive Asian elephants surveyed in Nepal are infected with Fasciola (Karki 2008).

The high overall prevalence of Fasciola found in Bornean elephants may be associated with the wet tropical conditions in Sabah, which are ideal for the complex, freshwater-dependent life cycle of Fasciola species. Fasciola ova hatch and release miracidia, which enter aquatic lymnaeid snails, develop through several life stages in these intermediate hosts and eventually emerge from the snails as cercariae, which encyst on aquatic plants. Cercariae mature into metacercariae (infective stage) and definitive hosts become infected by ingesting vegetation or water harbouring metacercariae (Taylor et al. 2013). Metacercariae can persist for up to 8 mo in moist conditions and fodder such as that upon which wild Bornean elephants feed (Fowler \& Mikota 2006).

There are several possible factors which may contribute to the observed higher Fasciola prevalence and load in the TWR compared with the LKWS. Intermediate hosts for Fasciola, aquatic lymnaeid snails, may be more abundant in the TWR compared with the LKWS, increasing the probability that infectious metacercariae are present in the TWR. Water bodies in some parts of the TWR are further away from palm oil plantations than water bodies in the LKWS. Therefore, water bodies in the LKWS may contain greater levels of agricultural pollutants such as palm oil mill effluent than those in the TWR. Palm oil mill effluent is generally $\mathrm{pH} 4$ to 5 due to organic acids produced in the fermentation process (Ma 1999, Lorestani 2006), but lymnaeid snails prefer near-neutral pH (Laursen et al. 1989). Alternatively, Bornean elephants in the TWR may feed on aquatic vegetation more frequently than those in the LKWS, as anthropogenic activities often impede access to the banks of the Kinabatangan River.

Factors influencing prevalence and load may vary depending on the species of Fasciola. Although ova 
could not be identified to species level in this study, they were likely to be either $F$. hepatica and/or $F$. jacksoni (Fowler \& Mikota 2006, Karki 2008). Fasciola jacksoni is an Asian-elephant-specific fasciolid, whereas a variety of mammals play host to $F$. hepatica; thus prevalence and load are affected by a suite of other epidemiological factors, such as density of livestock in surrounding areas (Ai et al. 2011). Further research, including species differentiation, observations of Bornean elephant feeding behaviour, water quality assessments and lymnaeid snail surveys, are warranted.

The prevalence of trematodes correlates positively with the abundance of definitive wildlife hosts of various taxa (Fredensborg et al. 2006, Byers et al. 2011). Following this pattern, significant differences in prevalence of Fasciola in the TWR compared with the LKWS may reflect a greater total number of Bornean elephants at the former site (Alfred et al. 2010).

A high prevalence and load of Anoplocephala in other herbivores is associated with sustained grazing of permanent pasture and microenvironmental conditions favourable to oribatid mites, the intermediate hosts of Anoplocephala (Ihler et al. 1995, McAloon 2004). In the LKWS, habitat fragmentation precludes Bornean elephant movement to new feeding grounds. Consequently, the sustained use of existing feeding grounds by Bornean elephants in the LKWS over numerous consecutive years is likely to increase the prevalence and load of Anoplocephala as well as strongyle nematodes.

Strongyles are inadvertently ingested by their hosts as infective third-stage larvae on vegetation. The overall high prevalence and load of strongyle nematodes indicates a high potential for faecal-oral transmission of parasites and pathogens in Bornean elephants. The high prevalence of strongyles is particularly concerning as parasites whose transmission is facilitated by close contact have been shown to be more likely to increase the risk of extinction compared with those transmitted by other routes (Pedersen et al. 2007).

The higher population density of Bornean elephants in the LKWS compared with the TWR is a plausible explanation for the significantly higher prevalence and load of strongyles in the former population. High population density facilitates faecaloral transmission and is a key factor contributing to prevalence, load and diversity of nematodes (Wiergertjes \& Flik 2004, Lebarbenchon et al. 2006).

Alternative explanations for the higher strongyle prevalence in the LKWS compared with the TWR include physiological and nutritional stress. Stress affects host immunity and predisposes animals to parasite infection (Dhabhar \& McEwen 1997, Agarwal \& Marshall 2001). Nutritional stress such as limited food availability and deficiencies in dietary components, particularly protein and energy, influence susceptibility to parasites and pathogens (Chapman et al. 2006b). Dietary stress and parasitism in African elephants Loxodonta africana in Kenya have a synergistic effect, leading to mass mortalities (Obanda 2011). Bornean elephants in the fragmented habitat of the LKWS may also experience stress associated with frequent and intense anthropogenic activities, though further research is required to confirm this assumption. Further studies to investigate physiological parameters, particularly faecal glucocorticoid metabolites, are warranted.

The frequency of mixed infections suggests that Bornean elephants are susceptible to a myriad of parasites and that environmental conditions in Sabah are conducive to parasite survival and transmission. These conditions make parasitological research all the more relevant for the conservation of wildlife and their symbiotic fauna in Borneo, a global biodiversity hotspot (Gómez et al. 2012). A higher frequency of mixed infections in the continuous forest of the TWR compared with the fragmented habitat of the LKWS may be a reflection of overall biodiversity in continuous versus fragmented habitat. Continuous habitat harbours greater species diversity than smaller, more disconnected patches, and this concept may also apply to parasites (MacArthur \& Wilson 1967, Robinson \& Quinn 1992, Fahrig 2003, Nunn et al. 2003).

Parasite overdispersion, the variable distribution of parasites in any given animal population whereby the majority of parasites is found in a small fraction of the host population, is a central paradigm in parasite ecology because factors that produce overdisperson are key to understanding host parasite co-evolution, infection dynamics and disease risk (Wilson et al. 2003). Mortality and morbidity associated with parasites is typically dose-dependent and therefore has the greatest impact on the small fraction of hosts that harbour the majority of parasites (Wilson et al. 2003). $\mathrm{VAR}>1$ indicates an overdispersion of parasites in endangered Bornean elephants, which may be determined by heterogeneity of gender, age, body condition, exposure, genetics, immunity, feeding behaviour and habitat characteristics (Wassom et al. 1986). Further research is warranted to improve our understanding of how these factors affect parasite overdispersion and, consequently, host survival. In particular, overdispersion of strongyle nematodes in the densely populated LKWS demands attention because it has been shown that overdispersion is a key 
determinant of the degree to which population density affects infection dynamics (Churcher et al. 2005)

Limitations of this study include small sample size, limited temporal and spatial scale and difficulties associated with confounding host, parasite and environment variables, which affect parasite infection dynamics (Vidya \& Sukumar 2002). Due to terrain, visibility, practical limitations, safety concerns and time constraints, it was not possible during this study to approach Bornean elephants closely to identify individuals, establish demographics or perform even basic clinical assessments as performed in largescale, long-term parasite surveys of Asian elephants in more open habitat (Vidya \& Sukumar 2002). A longitudinal study could address sample duplication and improve the reliability of prevalence data. Further, more accurate and sophisticated parasite identification techniques may also be available for use in the future with the recent development of the first DNA markers to identify strongyle species in African elephants (McLean et al. 2012).

This study provides the baseline data necessary for further studies on parasites of endangered Bornean elephants in a conservation context and highlights the need for future research on infectious agents of species of conservation concern.

Acknowledgements. We thank Dr. L. Ambu for permission to carry out research in Sabah. Many thanks to M. Rampangajouw, B. Bin Resake, S. Bin Laimun, S. Bin Payar, D. Stark and P. Gardner from DFGC for their help and to field assistants A.S. Kapar, A. Abdullah, A. David and S. Putra. S.H. thanks S. Mikota, T. Gillespie, L. Yon, T. Sainsbury and E. Harris for their advice, D. Modry for his guidance on sample collection, D. Emery for loan of equipment and E.J. Milner-Gulland and M. Rowcliffe for their support. This study was supported by grants from the Rufford Small Grants Foundation, ZSL Erasmus Barlowe Darwin Expeditions Grant, Chester Zoo and Imperial College. This project is part of a larger Bornean elephant research and conservation program led by the Sabah Wildlife Department and Danau Girang Field Centre, funded by Elephant Family, Houston Zoo, Columbus Zoo, Mohamed bin Zayed Species Conservation Fund and the US Fish and Wildlife Service Asian Elephant Conservation Fund. Funding agencies had no role in the study design, data collection and analysis, decision to publish or preparation of the manuscript.

\section{LITERATURE CITED}

Agarwal SK, Marshall GD Jnr (2001) Stress effects on immunity and its application to clinical immunology. Clin Exp Allergy 31:25-31

Ai L, Chen MX, Alasaad S, Elsheikha HM and others (2011) Genetic characterization, species differentiation and detection of Fasciola spp. by molecular approaches. Parasites Vectors 4:101

Alfred R, Ahmad AH, Payne J, William C, Ambu L (2010) Density and population estimation of the Bornean elephant in Sabah. J Biol Sci 10:92-102
Ambu L, Angua PM, Nathan S, Tuuga A, Jensen SM, Cox R, Alfred R (2012) Asian elephant action plan. Sabah Wildlife Department, Kota Kinabalu

Anderson RM, May RM (1982) Coevolution of hosts and parasites. Parasitology 85:411-426

Blagburn BL, Butler JM (2006) Optimise intestinal parasite detection with centrifugal faecal flotation. Vet Med 101:455-463

Byers JE, Altman I, Grosse AM, Huspeni TC, Maerz JC (2011) Using trematode larvae to quantify an elusive vertebrate host. Conserv Biol 25:85-93

Campos-Arceiz A, Corlett RT (2011) Big animals in a shrinking world-studying the ecological role of Asian megafauna as agents of seed dispersal. Innovation 10:50-53

Chandrasekharan $\mathrm{K}$, Radhakrishnan $\mathrm{K}$, Cheeran JV, Muraleedharan NKN, Prabhakaran T (2009) Review of the incidence, aetiology and control of common diseases of Asian elephants with special reference to Kerala. In: Ajitkumar G, Anil KS, Alex PC (eds) Healthcare management of captive Asian elephants. Kerala Agricultural University Press, Pookot, p 92-95

Chapman CA, Speirs ML, Gillespie TR, Holland T, Austad KM (2006a) Life on the edge: gastrointestinal parasites from the forest edge and interior primate groups. Am J Primatol 68:397-409

> Chapman CA, Wasserman MD, Gillespie TR, Speirs ML, Lawes MJ, Saj TL, Ziegler TE (2006b) Do food availability parasitism and stress have synergistic effects on red colobus populations living in forest fragments? Am J Phys Anthropol 131:525-534

Choudhury A, Lahiri Choudhury DK, Desai A, Duckworth JW and others (IUCN SSC Asian Elephant Specialist Group) (2008) Elephas maximus. In: IUCN 2011. IUCN Red List of Threatened Species. Version 2011 2. Available at www. iucnredlist.org

Churcher TS, Ferguson NM, Basanez MG (2005) Density dependence and overdispersion in the transmission of helminth parasites. Parasitology 131:121-132

Coulon A, Cosson JF, Angibault JM, Galan M and others (2004) Landscape connectivity influences gene flow in a roe deer population inhabiting a fragmented landscape: an individual-based approach. Mol Ecol 13:2841-2850

> Deem SL, Karesh WB, Weisman W (2001) Putting theory into practice: wildlife health in conservation. Conserv Biol 15: 1224-1233

> Dhabhar FS, McEwen B (1997) Acute stress upregulates while chronic stress downregulates cell mediated immunity in vivo. Brain Behav Immun 11:286-306

Fahrig L (2003) Effects of habitat fragmentation on biodiversity. Annu Rev Ecol Evol Syst 34:487-515

> Fernando P, Vidya TNC, Payne J, Stuewe M and others (2003) DNA analysis indicates that Asian elephants are native to Borneo and are therefore a high priority for conservation. PLoS Biol 1:e6

Fowler ME, Mikota SK (2006) Biology, medicine and surgery of elephants. Blackwell Science, Oxford, p 159-181

> Fredensborg BL, Mouritsen KN, Poulin R (2006) Relating bird host distribution and spatial hetereogeneity in trematodes infection in an intertidal snail - from small to large scale. Mar Biol 149:275-283

> Gillespie TR, Chapman CA (2006) Prediction of parasite infection dynamics in primate metapopulations based on attributes of forest fragmentation. Conserv Biol 20:441-448

Gómez A, Nichols ES, Perkins SL (2012) Parasite conservation, conservation medicine and ecosystem health. In: Aguirre AA, Ostfeld RS, Daszak P (eds) New directions in conservation medicine: applied cases of ecological health. Oxford University Press, Oxford, p 67-81 
Gregory RD, Hudson PJ (2000) Parasites take control. Nature 406:33-34

Gulland FMD (1995)The impact of infectious diseases on wild animal populations: a review. In: Grenfell BT, Dobson AP (eds) Ecology of infectious diseases in natural populations. Cambridge University Press, Cambridge, p 20-51

> Hechinger RF, Lafferty KD (2005) Host diversity begets parasite diversity: bird final hosts and trematodes in snail intermediate hosts. Proc Biol Sci 272:1059-1066

Ihler CF, Rootwelt V, Heyeraas A, Dolvik NI (1995) The prevalence and epidemiology of Anoplocephala perfoliata infection in Norway. Vet Res Commun 19:487-494

Karki K (2008) Incidence of gastrointestinal helminths in captive elephants in wildlife reserves of Nepal. Available at www.articlesbase.com/health-articles/incidenceof-gastrointestinal-helminthes-in-captive-elephants-inwildlife-reserves-of-nepal-335689.html

Lafferty KD (1997) Environmental parasitology: What can parasites tell us about human impacts on the environment? Parasitol Today 13:251-255

Laursen JR, Averbeck GA, Conboy GA (1989) Preliminary survey of pulmonate snails of central Minnesota. Final report submitted to the Nongame Wildlife Program, Minnesota Department of Natural Resources. University of Minnesota, St. Paul, MN

Lebarbenchon C, Poulin R, Gautheir-Clerc M, Thomas F (2006) Parasitological consequences of overcrowding in protected areas. EcoHealth 3:303-307

Lorestani AAZ (2006) Biological treatment of palm oil effluent (POME) using an upflow anaerobic sludge fixed film (UASFF) bioreactor. Report for The Universiti Sains Malaysia, Penang

Ma ANMA (1999) Treatment of palm oil mill effluent. In: Singh G, Huan LK, Leng T, Kow DL (eds) Oil palm and the environment - a Malaysian perspective. Malaysian Palm Oil Grower's Council, Kuala Lumpur, p 113-123

MacArthur RH, Wilson EO (1967) The theory of island biogeography. Princeton University Press, Princeton, NJ

Mar KU (2007) The demography and life-history strategies of timber elephants of Myanmar. PhD dissertation, University College London, London

Marcogliese DJ (2004) Parasites: small players with crucial roles in the ecological theatre. EcoHealth 1:151-164

Marcogliese DJ (2005) Parasites of the superorganism: Are they indicators of ecosystem health? Int J Parasitol 35: 705-716

Mathews F (2009) Zoonoses in wildlife: integrating ecology into management. Adv Parasitol 68:185-209

Mbora DNM, McPeek MA (2009) Host density and human activities mediate increased parasite prevalence and richness in primates threatened by habitat loss and fragmentation. J Anim Ecol 78:210-218

McAloon FM (2004) Oribatid mites as intermediate hosts of Anoplocephala manubriata, cestode of the Asian elephant in India. Exp Appl Acarol 32:181-185

McCallum H, Dobson A (2002) Disease, habitat fragmentation and conservation. Proc Biol Sci 269:2041-2049

McLean ER, Kinsella JM, Chiyo P, Obanda V, Moss C, Archie EA (2012) Genetic identification of five strongyle nematode parasites in wild African elephants Loxodonta africana. J Wildl Dis 48:707-716

MAFF (Ministry of Agriculture Fisheries and Food UK) (1986) Manual of veterinary parasitological laboratory techniques. Freeman, New York, NY

Nelson A, Bidwell P, Sillero-Zubiri C (2003) A review of humane elephant conflict management strategies. Report by The People and Wildlife Initiative, Oxford University
Wildlife Conservation Research Unit, available at www. peopleandwildlife.org.uk/crmanuals/

Nichols E, Gómez A (2011) Conservation education needs more parasites. Biol Conserv 144:937-941

> Nunn CL, Altizer S, Jones KE, Sechrest W (2003) Comparative tests of parasite species richness in primates. Am Nat 162: $597-614$

Obanda V (2011) Gastrointestinal parasites and associated pathological lesions in starving free-ranging African elephants. S Afr J Wildl Res 41:167-172

Othman N, Maryati M, Ahmad AH, Nathan KSS, Pierson HT, Goossens B (2008) A preliminary study on the morphometrics of the Bornean elephant. J Trop Biol Conserv 4:1109-1113

Page LK, Swihart RK, Kazacos KR (2001) Changes in transmission of Baylisascaris procyonis to intermediate hosts as a function of spatial scale. Oikos 93:213-220

Pedersen AB, Jones KE, Nunn CL, Altizer S (2007) Infectious diseases and extinction risk in wild mammals. Conserv Biol 21:1269-1279

Robinson GR, Quinn JF (1992) Habitat fragmentation, species diversity, extinction and design of nature reserves. In: Jain SK, Botsford LW (eds) Applied population biology, Vol 67. Springer, Dordrecht, p 223-248

Saseendran PC, Rajendran S, Subramanian H, Sasikumar M, Vivek G, Anil KS (2004) Incidence of helminthic infection among annually dewormed captive elephants. Zoos Print J 19:1422

Schwitzer N, Clough D, Zahner H, Kaumanns W, Kappeler P, Schwitzer C (2010) Parasite prevalence in blue-eyed black lemurs Eulemur flavifrons in differently degraded forest fragments. Endang Species Res 12:215-225

Stremme C, Lubis A, Wahyu M (2007) Implementation of regular veterinary care for captive Sumatran elephants. Gajah 27:6-14

Sukumar R (2003) The living elephants. Oxford University Press, Oxford, p 353-363

Suzan G, Esponda F, Carrasco-Hernandez R, Aguirre A (2012) Habitat fragmentation and infectious disease ecology. In: Aguirre AA, Ostfeld RS, Daszak P (eds) New directions in conservation medicine - applied cases of ecological health. Oxford University Press, Oxford, p 135-150

Taylor MA, Coop RL, Wall RL (2013) Veterinary parasitology. Blackwell, Oxford

Toft CA, Karter AJ (1990) Parasite-host coevolution. Trends Ecol Evol 5:326-329

Vidya TNC, Sukumar R (2002) The effect of some ecological factors on the intestinal parasite loads of the Asian elephant Elephas maximus in southern India. J Biosci 27: 521-528

> Wassom DL, Dick TA, Amason N, Strickland D, Grundmann AW (1986) Host genetics: a key factor in regulating the distribution of parasites in natural host populations. J Parasitol 72:334-337

Whiteman NK, Parker PG (2005) Using parasites to infer host population history: a new rational for parasite conservation. Anim Conserv 8:175-181

Wiergertjes GF, Flik G (2004) Host-parasite interactions. Garland Science, New York, NY

Wilson K, Bjornstad ON, Dobson AP, Merler S and others (2003) Chapter 2 Heterogeneities in macroparasite infections: patterns and processes. In: Hudson PJ, Rizzoli A, Grenfell BT, Heesterbeek H, Dobson AP (eds) The ecology of wildlife diseases. Oxford University Press, New York, NY, p 6-44

Zhang JS, Daszak P, Huang HL, Yang GY, Kilpatrick AM, Zhang S (2008) Parasite threat to panda conservation. EcoHealth 5:6-9 